\title{
Preoperative serum thyroglobulin is a risk factor of skip metastasis in papillary thyroid carcinoma
}

\author{
Ziyang Huang ${ }^{1,2 \#}$, Muye Song ${ }^{1,3 \#}$, Shujie Wang ${ }^{1,4 \#}$, Jianhao Huang $^{1,2}$, Hongyan Shi ${ }^{1,4}$, Yijie Huang ${ }^{1}$, Ying Yin $^{1}$, \\ Yongchen $\mathrm{Liu}^{1}$, Zeyu $\mathrm{Wu}^{1}$ \\ ${ }^{1}$ Department of General Surgery, Guangdong Provincial People's Hospital, Guangdong Academy of Medical Sciences, Guangzhou 510080, China; \\ ${ }^{2}$ Shantou University Medical College, Shantou 515041, China; ${ }^{3}$ School of Medicine, South China University of Technology, Guangzhou 510006, \\ China; ${ }^{4}$ The Second School of Clinical Medicine, Southern Medical University, Guangzhou 510515, China \\ Contributions: (I) Conception and design: Z Huang, M Song, S Wang; (II) Administrative support: Y Liu, Z Wu; (III) Provision of study materials \\ or patients: All authors; (IV) Collection and assembly of data: Z Huang, M Song, S Wang, J Huang, H Shi; (V) Data analysis and interpretation: Z \\ Huang, M Song, S Wang; (VI) Manuscript writing: All authors; (VII) Final approval of manuscript: All authors. \\ "These authors contributed equally to this work. \\ Correspondence to: Zeyu Wu; Yongchen Liu. Department of General Surgery, Guangdong Provincial People's Hospital, Guangdong Academy of \\ Medical Sciences, 106 Zhong Shan Second Road, Guangzhou 510080, China. Email: wu.zeyu@hotmail.com; avatarlara@163.com.
}

\begin{abstract}
Background: Lymph node metastasis of papillary thyroid carcinoma (PTC) was a significant risk factor of local recurrence and distant metastasis, and our study aimed to identify predictive factors of skip metastasis in PTC, helping surgeons to build a strategy when facing patients in N1b stage with clinical central lymph node-negative.

Methods: A total of 304 patients who underwent total thyroidectomy with central and lateral lymph node dissection and were diagnosed PTC with lateral lymph node metastasis (LLNM) in the Department of General Surgery at Guangdong Provincial People's Hospital were enrolled. We collected clinicopathological characteristics and analyzed their correlation with skip metastasis by univariate and multivariate analysis.

Results: The incidence of skip metastasis in PTC was 14.8\%. Univariate analysis showed that age, tumor diameter, primary tumor location, and preoperative serum thyroglobulin ( Tg) were risk factors. Age $(\mathrm{P}=0.049$, $\mathrm{OR}=3.418)$, primary tumor location $(\mathrm{P}<0.001$, $\mathrm{OR}=7.279)$, and $\mathrm{Tg}(\mathrm{P}=0.038, \mathrm{OR}=9.412)$ were independent predictors in PTC by multivariate analysis.

Conclusions: Skip metastasis of PTC was significantly associated with preoperative serum $\mathrm{Tg} \leq 77 \mathrm{ng} / \mathrm{mL}$, tumor diameter $\leq 10 \mathrm{~mm}$, age $\geq 55$, and tumor located in the upper lobe. It is the first time to demonstrate that $\mathrm{Tg}$ is associated with skip metastasis of PTC.
\end{abstract}

Keywords: Lymphatic metastasis; thyroid neoplasms; thyroglobulin

Submitted Oct 15, 2019. Accepted for publication Nov 21, 2019.

doi: 10.21037/atm.2019.10.92

View this article at: http://dx.doi.org/10.21037/atm.2019.10.92

\section{Introduction}

The incidence rate of thyroid cancer continues to increase, and papillary thyroid carcinoma (PTC) represents the most common subtype of thyroid cancer $(1,2)$. PTC prefers to metastasize through the lymphatic channel, and lymph node metastasis can be found in $27-80 \%$ of PTC patients, which is a significant risk factor of local recurrence and distant metastasis (3-6). Traditionally, the central lymph node compartment is regarded as the first metastatic site, and the lateral cervical compartment is the subsequent site, basing on the anatomic lymphatic channels (7). However, skip metastasis, defined as jump metastasis to the lateral neck without central lymph node metastasis (CLNM), sometimes happens (8). According to the previous studies, the incidence of skip lymph node metastasis ranges from 
$6.8-37.5 \%$ in PTC (8-11). And lymph node metastasis is significantly associated with recurrence of PTC $(12,13)$. However, clinical and pathological risk factors for skip metastasis of PTC remain uncertain.

Recently, the utility of preoperative serum thyroglobulin ( $\mathrm{Tg}$ ) in the diagnosis and evaluation of differentiated thyroid carcinoma (DTC) raises clinicians' notice. Some research demonstrated a significantly higher level of preoperative serum $\mathrm{Tg}$ in DTC patients and found preoperative serum $\mathrm{Tg}$ was a predictive factor for metastasis of DTC patients (14-17). Less research studied the relation between preoperative serum $\mathrm{Tg}$ and lymph node metastasis. Furthermore, no study explored whether preoperative serum Tg was making an influence in skip metastasis of PTC.

We focused our study on investigating the predictive factors of skip metastasis in PTC patients. Not only did we study the clinicopathological characteristics, but we also included several common laboratory indexes, such as preoperative serum $\mathrm{Tg}$, anti-thyroglobulin antibody (TGAb), anti-thyroid peroxidase antibody (A-TPO) and thyrotropin receptor antibody (TRAb).

\section{Methods}

\section{General clinical materials}

Patients with suspicious of PTC and LLNM who underwent total thyroidectomy with central and lateral lymph node dissection were reviewed retrospectively in this study. The reservation upon them lasts from October 2015 to June 2019, carried in the Department of General Surgery at Guangdong Provincial People's Hospital. Preoperative assessment of lymph node metastasis included ultrasonic examination (US), neck computed tomography scan (CT), and positron emission tomography-computed tomography (PET-CT). The US was routinely performed to assess the lymph node status in all these patients. CT and PET-CT were used only in some patients as needed. Fineneedle aspiration (FNA) was not used for the diagnosis of lymph node metastasis routinely in our hospital. The levels of serum $\mathrm{Tg}$ (normal value ranges from 3.5-77 $\mathrm{ng} / \mathrm{mL}$ ), TGAb (normal value ranges from $0-115 \mathrm{IU} / \mathrm{mL}$ ), A-TPO (normal value ranges from 0-34 IU/mL) and TRAb (normal value ranges from 0-1.75 IU/L) were measured in the Laboratory Department of our hospital within one month before surgery. Patients were diagnosed with PTC with LLNM by general pathological examination in the
Pathology Department of our hospital; what all of them received is their very first treatment. The central lymph node dissection in our department is performed superiorly to the thyroid cartilage, inferiorly to the innominate vein, laterally to the carotid sheaths and posteriorly to the prevertebral fascia. Lateral lymph node dissection is performed superiorly to the posterior belly of the digastric muscle, inferiorly to the subclavian vein, and laterally to the anterior border of the trapezius muscle, which is also called level II-V dissection.

Some patients were excluded from our study basing on any one of the following criteria: no lateral lymph node metastasis (LLNM), no complete ipsilateral central plus lateral lymph node dissection, received prior surgery or radiotherapy of the neck, combined with other types of thyroid malignancy, bilateral tumors or tumors in the isthmus, combined with other distant metastasis. Finally, the total number of 304 patients met our criteria.

\section{Statistical analysis}

Data collection was performed using Microsoft Excel. Statistical analysis was performed by using IBM SPSS statistics 25.0 software. Univariate analyses by the $X^{2}$ test or Fisher's exact test were performed to investigate the relationships between PTC and clinicopathologic characteristics. Multivariate analysis was performed by binary logistic regression. $\mathrm{P}$ values $<0.05$ were considered statistically significant.

\section{Results}

\section{Characteristics of patient and tumor}

In this study, 304 patients met our criteria were enrolled. Among them, 191 (62.8\%) of them were women, and 113 $(37.2 \%)$ were men. The mean age was $37.9 \pm 13.0$ years, ranging from 5 years to 76 years, and there were $39(12.8 \%)$ patients aged $\geq 55$ years and $265(87.2 \%)$ aged $<55$ years. Papillary thyroid microcarcinoma (PTMC) was found in 95 (31.3\%) patients, while conventional PTC (CPTC, tumor with a maximum diameter of more than $10 \mathrm{~mm}$ ) was found in 209 (68.8\%) patients. A total of 127 patients exhibited capsule invasion, and 64 exhibited extracapsular extension. Seventy-seven (25.3\%) patients were diagnosed with autoimmune thyroid disease by general pathological examination. Ninety-eight $(32.2 \%)$ of the primary tumors located in the upper lobe and 148 (48.7\%) were in the 
Table 1 Patient demographics and clinicopathological characteristics $(\mathrm{n}=304)$

\begin{tabular}{|c|c|}
\hline Characteristics & Results \\
\hline \multicolumn{2}{|l|}{ Gender } \\
\hline Male & 113 \\
\hline Female & 191 \\
\hline Age $($ mean $\pm S D)$ & $37.9 \pm 13.0$ \\
\hline$<55$ years & 265 \\
\hline$\geq 55$ years & 39 \\
\hline \multicolumn{2}{|l|}{ Tumor diameter } \\
\hline$\leq 10 \mathrm{~mm}$ & 95 \\
\hline$>10 \mathrm{~mm}$ & 209 \\
\hline \multicolumn{2}{|l|}{ Capsule invasion } \\
\hline Yes & 127 \\
\hline No & 177 \\
\hline \multicolumn{2}{|c|}{ Extracapsular extension } \\
\hline Yes & 64 \\
\hline No & 240 \\
\hline \multicolumn{2}{|c|}{ Primary tumor location } \\
\hline Upper & 98 \\
\hline Others & 148 \\
\hline Cannot define & 58 \\
\hline \multicolumn{2}{|c|}{ Autoimmune thyroid disease } \\
\hline Yes & 77 \\
\hline No & 227 \\
\hline \multicolumn{2}{|l|}{ Multifocality } \\
\hline Yes & 132 \\
\hline No & 172 \\
\hline \multicolumn{2}{|l|}{$\operatorname{Tg}$} \\
\hline$\leq 77 \mathrm{ng} / \mathrm{mL}$ & 161 \\
\hline$>77 \mathrm{ng} / \mathrm{mL}$ & 45 \\
\hline \multicolumn{2}{|l|}{ TGAb } \\
\hline$\leq 115 \mathrm{IU} / \mathrm{mL}$ & 122 \\
\hline$>115 \mathrm{IU} / \mathrm{mL}$ & 47 \\
\hline \multicolumn{2}{|l|}{ A-TPO } \\
\hline$\leq 34 \mathrm{IU} / \mathrm{mL}$ & 122 \\
\hline$>34 \mathrm{IU} / \mathrm{mL}$ & 37 \\
\hline
\end{tabular}

Table 1 (continued)
Table 1 (continued)

\begin{tabular}{lc}
\hline Characteristics & Results \\
\hline TRAb & \\
$\leq 1.75 \mathrm{IU} / \mathrm{L}$ & 85 \\
$>1.75 \mathrm{IU} / \mathrm{L}$ & 13 \\
Skip metastases & \\
Yes & 45 \\
No & 259 \\
\hline
\end{tabular}

Tg, thyroglobulin; TGAb, anti-thyroglobulin antibody; A-TPO, anti-thyroid peroxidase antibody; TRAb, thyrotropin receptor antibody.

middle or lower lobe. There were 58 patients that we could not define the locations of the tumor. Normal $\mathrm{Tg}$ ( $\mathrm{Tg}$ $\leq 77 \mathrm{ng} / \mathrm{mL}$ ) was shown in 161 patients, while 45 patients had elevated $\mathrm{Tg}(\mathrm{Tg}>77 \mathrm{ng} / \mathrm{mL})$; the other 98 patients did not measure serum $\mathrm{Tg}$ before surgery. And details of thyroid autoantibody were shown in Table 1. Among all the patients, $45(14.8 \%)$ were diagnosed as skip metastases.

\section{Predictive factors of skip metastasis in PTC}

In the univariate analyses, as shown in Table 2, we found that skip metastasis was significantly related to age $(\mathrm{P}=0.041)$, tumor diameter $(\mathrm{P}=0.006)$, primary tumor location $(\mathrm{P}<0.001)$ and preoperative serum $\mathrm{Tg}(\mathrm{P}=0.043)$. There were no significant differences in other clinicopathological factors such as capsule invasion, extracapsular extension, multifocality, autoimmune thyroid disease, TGAb, A-TPO, or TRAb. For the multivariate analysis, a binary logistic regression was performed, and it revealed age $(\mathrm{P}=0.049, \mathrm{OR}=3.418,95 \% \mathrm{CI}: 1.006-11.612)$, primary tumor location $(\mathrm{P}<0.001$, OR $=7.279,95 \%$ CI: 2.668 19.856) and $\mathrm{Tg}(\mathrm{P}=0.038, \mathrm{OR}=9.412,95 \% \mathrm{CI}: 1.126-78.664)$ were independent predictors of skip metastases, as shown in Table 3.

\section{Discussion}

From the traditional point of view, lymphatic metastasis first takes place in the central compartment and invades the lateral sections subsequently (9). It relaxes our vigilance when the central compartment comes negative. Consequently, we may underestimate the risk of LLNM. In our study, the incidence of skip metastasis is $14.8 \%$. According to the previous studies, the incidence of skip 
Table 2 Univariate analysis of the risk factors of PTC

\begin{tabular}{|c|c|c|c|}
\hline Characteristics & Skip (-) & Skip (+) & $P$ value \\
\hline Gender & & & 0.808 \\
\hline Male & 97 & 16 & \\
\hline Female & 162 & 29 & \\
\hline Age & & & $0.041^{*}$ \\
\hline$<55$ years & 230 & 35 & \\
\hline$\geq 55$ years & 29 & 10 & \\
\hline Tumor diameter & & & $0.006^{*}$ \\
\hline$\leq 10 \mathrm{~mm}$ & 73 & 22 & \\
\hline$>10 \mathrm{~mm}$ & 186 & 23 & \\
\hline Capsule invasion & & & 0.359 \\
\hline Yes & 111 & 16 & \\
\hline No & 148 & 29 & \\
\hline Extracapsular extension & & & 0.559 \\
\hline Yes & 56 & 8 & \\
\hline No & 203 & 37 & \\
\hline Primary tumor location & & & $<0.001^{*}$ \\
\hline Upper & 71 & 27 & \\
\hline Others & 135 & 13 & \\
\hline Multifocality & & & 0.616 \\
\hline Yes & 114 & 18 & \\
\hline No & 145 & 27 & \\
\hline Autoimmune thyroid disea & & & 0.087 \\
\hline Yes & 61 & 16 & \\
\hline No & 198 & 29 & \\
\hline $\operatorname{Tg}$ & & & $0.043^{*}$ \\
\hline$\leq 77 \mathrm{ng} / \mathrm{mL}$ & 135 & 26 & \\
\hline$>77 \mathrm{ng} / \mathrm{mL}$ & 43 & 2 & \\
\hline TGAb & & & 0.485 \\
\hline$\leq 115 \mathrm{IU} / \mathrm{mL}$ & 104 & 18 & \\
\hline$>115 \mathrm{IU} / \mathrm{mL}$ & 38 & 9 & \\
\hline A-TPO & & & 0.175 \\
\hline$\leq 34 \mathrm{IU} / \mathrm{mL}$ & 101 & 21 & \\
\hline$>34 \mathrm{IU} / \mathrm{mL}$ & 34 & 3 & \\
\hline TRAb & & & 0.765 \\
\hline$\leq 1.75 \mathrm{IU} / \mathrm{L}$ & 65 & 20 & \\
\hline$>1.75 \mathrm{IU} / \mathrm{L}$ & 11 & 2 & \\
\hline
\end{tabular}

*, symbol for statistically significance. PTC, papillary thyroid carcinoma; Tg, thyroglobulin; TGAb, anti-thyroglobulin antibody; A-TPO, anti-thyroid peroxidase antibody; TRAb, thyrotropin receptor antibody.
Table 3 Multivariate analysis of the risk factors of PTC

\begin{tabular}{lccc}
\hline Characteristics & P value & OR & $95 \% \mathrm{Cl}$ \\
\hline Age $(\geq 55 /<55$ years) & 0.049 & 3.418 & $1.006-11.612$ \\
$\begin{array}{l}\text { Primary tumor location } \\
\text { (upper/others) }\end{array}$ & $<0.001$ & 7.279 & $2.668-19.856$ \\
Tg $(\leq 77 />77 \mathrm{ng} / \mathrm{mL})$ & 0.038 & 9.412 & $1.126-78.664$ \\
\hline
\end{tabular}

PTC, papillary thyroid carcinoma; Tg, thyroglobulin.

metastasis ranged from $6.8-37.5 \%$ (8-11), which could not be ignored in clinical practice. Although the significance of skip metastasis of PTC is unclear, other malignancies, such as gastric cancer and non-small cell lung cancer, were reported to have a bad influence on prognosis $(18,19)$. Thus, it is urgent to determine the risk factor of skip metastasis.

In our study, we found tumor diameter $\leq 10 \mathrm{~mm}$ was a statistically risk factor by univariate analysis. It was also confirmed by other researchers $(9,11,20,21)$. However, we found no significant difference using multivariate analysis. Most of the studies used $10 \mathrm{~mm}$ as the cutoff point. Nie et al. highlighted the correlation between tumor size $\leq 5 \mathrm{~mm}$ and skip metastasis (22). Therefore, the accurate cutoff point of tumor diameter needs further exploration. Besides, according to the American Joint Committee on Cancer (AJCC) thyroid cancer staging system $\left(8^{\text {th }}\right.$ edition), we applied the age of 55 as the cutoff value, and we found age $\geq 55$ was independently risk factors $(\mathrm{P}=0.049$, OR $=3.418)$. And PTC located in the upper lobe showed a remarkable difference in two PTC groups $(\mathrm{P}<0.001$, $\mathrm{OR}=7.279)$. Likhterov et al. explained in an anatomic level that different lymphatic channels drained the thyroid gland, and lymphatic drainage of the upper lobe may proceed along the superior pole vessels, bypassing the central compartment (7). Tumor site was accepted as a predictive factor of PTC (10,11,20-22).

Another novel finding was that normal $\mathrm{Tg}$ was more likely to present with skip metastasis than elevated $\mathrm{Tg}$ $(\mathrm{P}=0.038, \mathrm{OR}=9.412$, with $95 \% \mathrm{CI}$ : ranged from 1.126 78.664). $\mathrm{Tg}$ is a secretory protein synthesized in the thyrocyte endoplasmic reticulum, and its functions are iodide storage and thyroid hormonogenesis $(14,23)$. Tg is widely used for monitoring for DTC recurrence and diagnosis of lymphatic metastasis lymph node fine-needle aspiration biopsy $(24,25)$. However, whether preoperative serum $\mathrm{Tg}$ could predict the malignancy or lymphatic metastasis of PTC is still controversial. Patell et al. showed that there was no correlation between $\mathrm{Tg}$ and metastasis (26). 
On the contrary, some underlined preoperative serum $\mathrm{Tg}$ was at higher level in DTC patients than those with benign thyroid nodules, and it was an independent predictive factor of DTC (14-16). Scheffler et al. added Tg to the McGill thyroid nodule score (MTNS), a scoring system to evaluate the malignancy of thyroid nodules, finding that $\mathrm{Tg}$ could increase the sensitivity of the system (27). They used the cutoff value of $75 \mathrm{ng} / \mathrm{mL}$. Kim et al. discovered $\mathrm{Tg}>63.4 \mathrm{ng} / \mathrm{mL}$ was useful for predicting initial distant metastasis of DTC $(\mathrm{P}<0.05, \mathrm{OR}=9.412)(17)$. In our study, the incidence of skip metastasis in $\mathrm{Tg} \leq 77 \mathrm{ng} / \mathrm{mL}$ and $\mathrm{Tg}>77 \mathrm{ng} / \mathrm{mL}$ were $16.1 \%$ vs. $4.4 \%$, with a $\mathrm{P}$ value $<0.05$ in multivariate analysis. It was reasonable to assume that patients with elevated $\mathrm{Tg}$ were less likely to show skip metastasis. Thus, those patients tended to suffer central compartment metastasis. The mechanisms of how elevated $\mathrm{Tg}$ affects CLNM remains unclear. Low et al. proved a negative correlation between the number of central dissected lymph nodes and postoperative $\mathrm{Tg}$ (28). We speculated that the metastatic central tumor burden would increase the $\mathrm{Tg}$ level.

In consequence, patients with normal $\mathrm{Tg}$ were more likely to have a skip metastasis. In our study, 2 patients with elevated $\mathrm{Tg}$ showed a skip metastasis. One patient's Tg was $369.1 \mathrm{ng} / \mathrm{mL}$, with tumors located in the upper lobe, and he was 65 years old. So, it was inaccurate to predict a skip metastasis with a single factor. Another Tg was $135 \mathrm{ng} / \mathrm{mL}$, and the number of central dissected lymph nodes was only one. It may be falsely negative due to the inadequate dissection of central lymph nodes.

Our study aimed to identify predictive factors of skip metastasis in PTC, helping surgeons to build a strategy when facing patients in the N1b stage with clinical central lymph node-negative. However, mechanisms of some of our findings needed further explorations. We could not eliminate the interference of TGAb to serum Tg. Earlier studies had shown TGAb interference limited the utility of $\mathrm{Tg}$ as a tumor marker in about $30 \%$ of TGAb-positive patients $(29,30)$. Obtaining authentic $\mathrm{Tg}$ required special laboratory measurements, such as liquid chromatographytandem mass spectrometry (31). The instrumentation of laboratory limited it, and the potential benefits of those new methods were uncertain. So, we needed to study authentic $\mathrm{Tg}$ in our further research. In addition, selection bias was inevitable due to the reason that prophylactic lateral compartment dissection was not recommended by international guidelines, and all patients enrolled were confirmed with LLNM. Moreover, our study was only a single-center retrospective analysis. It needs to be further verified by multicenter prospective studies.

\section{Conclusions}

In this study, skip metastasis of PTC was significantly associated with preoperative serum $\mathrm{Tg}$, which was never published or analyzed by other researchers. Other risk factors were tumor diameter, tumor location, and age. And the independent predictors of skip metastasis in PTC were tumor diameter $\leq 10 \mathrm{~mm}$, age $\geq 55$, the tumor located in the upper lobe, and preoperative serum $\mathrm{Tg} \leq 77 \mathrm{ng} / \mathrm{mL}$. Thus, these factors are worth being considered by the surgeons when evaluating the risk of lymph node metastasis of PTC. However, the mechanism of skip metastasis remains uncertain, and it needs further explorations. Larger multicenter studies are necessary to be carried out to help clinicians build a strategy towards skip metastasis.

\section{Acknowledgments}

Funding: None.

\section{Footnote}

Conflicts of Interest: The authors have no conflicts of interest to declare.

Ethical Statement: The authors are accountable for all aspects of the work in ensuring that questions related to the accuracy or integrity of any part of the work are appropriately investigated and resolved. The study was approved by Research Ethics Committee of Guangdong Provincial People's Hospital, Guangdong Academy of Medical Sciences (No. GDREC2019780H).

Open Access Statement: This is an Open Access article distributed in accordance with the Creative Commons Attribution-NonCommercial-NoDerivs 4.0 International License (CC BY-NC-ND 4.0), which permits the noncommercial replication and distribution of the article with the strict proviso that no changes or edits are made and the original work is properly cited (including links to both the formal publication through the relevant DOI and the license). See: https://creativecommons.org/licenses/by-nc-nd/4.0/.

\section{References}

1. Siegel RL, Miller KD, Jemal A. Cancer statistics, 2019. 
CA Cancer J Clin 2019;69:7-34.

2. Chen $W$, Zheng R, Baade PD, et al. Cancer statistics in China, 2015. CA Cancer J Clin 2016;66:115-32.

3. Adam MA, Pura J, Goffredo P, et al. Presence and Number of Lymph Node Metastases Are Associated With Compromised Survival for Patients Younger Than Age 45 Years With Papillary Thyroid Cancer. J Clin Oncol 2015;33:2370-5.

4. Liang J. Is prophylactic central neck dissection necessary for $\mathrm{cN} 0$ differentiated thyroid cancer patients at initial treatment. 2017.

5. Liu X, Zhu L, Wang Z, et al. Evolutionary features of thyroid cancer in patients with thyroidectomies from 2008 to 2013 in China. Scientific Reports 2016;6:28414.

6. Mazzaferri EL. Management of a Solitary Thyroid Nodule. N Engl J Med 1993;328:553-9.

7. Likhterov I, Reis LL, Urken ML. Central compartment management in patients with papillary thyroid cancer presenting with metastatic disease to the lateral neck: Anatomic pathways of lymphatic spread. Head Neck 2017;39:853-9.

8. Attard A, Paladino NC, Lo Monte AI, et al. Skip metastases to lateral cervical lymph nodes in differentiated thyroid cancer: a systematic review. BMC Surg 2019;18:112.

9. Zhao H, Huang T, Li H. Risk factors for skip metastasis and lateral lymph node metastasis of papillary thyroid cancer. Surgery 2019;166:55-60.

10. Lee YS, Shin SC, Lim YS, et al. Tumor locationdependent skip lateral cervical lymph node metastasis in papillary thyroid cancer. Head Neck 2014;36:887-91.

11. Lei J, Zhong J, Jiang K, et al. Skip lateral lymph node metastasis leaping over the central neck compartment in papillary thyroid carcinoma. Oncotarget 2017;8:27022-33.

12. Kim H, Kim TH, Choe JH, et al. Patterns of Initial Recurrence in Completely Resected Papillary Thyroid Carcinoma. Thyroid 2017;27:908-14.

13. Jianyong L, Jinjing Z, Zhihui L, et al. A Nomogram Based on the Characteristics of Metastatic Lymph Nodes to Predict Papillary Thyroid Carcinoma Recurrence. Thyroid 2018;28:301-10.

14. Rinaldi S, Plummer M, Biessy C, et al. Thyroidstimulating hormone, thyroglobulin, and thyroid hormones and risk of differentiated thyroid carcinoma: the EPIC study. J Natl Cancer Inst 2014;106:dju097.

15. Trimboli P, Treglia G, Giovanella L. Preoperative measurement of serum thyroglobulin to predict malignancy in thyroid nodules: a systematic review.
Horm Metab Res 2015;47:247-52.

16. Herle AJ, Uller RP. Elevated serum thyroglobulin. A marker of metastases in differentiated thyroid carcinomas. J Clin Invest 1975;56:272-7.

17. Kim H, Kim YN, Kim HI, et al. Preoperative serum thyroglobulin predicts initial distant metastasis in patients with differentiated thyroid cancer. Sci Rep 2017;7:16955.

18. Choi YY, An JY, Guner A, et al. Skip lymph node metastasis in gastric cancer: is it skipping or skipped? Gastric Cancer 2016;19:206-15.

19. Prenzel KL, Monig SP, Sinning JM, et al. Role of skip metastasis to mediastinal lymph nodes in non-small cell lung cancer. J Surg Oncol 2003;82:256-60.

20. Park JH, Lee YS, Kim BW, et al. Skip lateral neck node metastases in papillary thyroid carcinoma. World J Surg 2012;36:743-7.

21. Jin WX, Jin YX, Ye DR, et al. Predictive Factors of Skip Metastasis in Papillary Thyroid Cancer. Med Sci Monit 2018;24:2744-9.

22. Nie X, Tan Z, Ge M. Skip metastasis in papillary thyroid carcinoma is difficult to predict in clinical practice. BMC Cancer 2017;17:702.

23. Di Jeso B, Arvan P. Thyroglobulin From Molecular and Cellular Biology to Clinical Endocrinology. Endocrine Reviews 2016;37:2-36.

24. Matana A, Popovic M, Boutin T, et al. Genetic Variants in the ST6GAL1 Gene Are Associated with Thyroglobulin Plasma Level in Healthy Individuals. Thyroid 2019;29:886-93.

25. Lee SH, Roh JL, Gong G, et al. Risk Factors for Recurrence After Treatment of N1b Papillary Thyroid Carcinoma. Ann Surg 2019;269:966-71.

26. Patell R, Mikhael A, Tabet M, et al. Assessing the utility of preoperative serum thyroglobulin in differentiated thyroid cancer: a retrospective cohort study. Endocrine 2018;61:506-10.

27. Scheffler P, Forest VI, Leboeuf R, et al. Serum thyroglobulin improves the sensitivity of the McGill Thyroid Nodule Score for well-differentiated thyroid cancer. Thyroid 2014;24:852-7.

28. Low TH, Delbridge L, Sidhu S, et al. Lymph node status influences follow-up thyroglobulin levels in papillary thyroid cancer. Ann Surg Oncol 2008;15:2827-32.

29. Algeciras-Schimnich A. Thyroglobulin measurement in the management of patients with differentiated thyroid cancer. Crit Rev Clin Lab Sci 2018;55:205-18. 
30. Cabaleiro DR, Stockl D, Kaufman JM, et al. Feasibility of standardization of serum C-peptide immunoassays with isotope-dilution liquid chromatography-tandem mass spectrometry. Clin Chem 2006;52:1193-6.

Cite this article as: Huang Z, Song M, Wang S, Huang J, Shi H, Huang Y, Yin Y, Liu Y, Wu Z. Preoperative serum thyroglobulin is a risk factor of skip metastasis in papillary thyroid carcinoma. Ann Transl Med 2020;8(6):389. doi: 10.21037/atm.2019.10.92
31. Hoofnagle AN, Roth MY. Clinical review: improving the measurement of serum thyroglobulin with mass spectrometry. J Clin Endocrinol Metab 2013;98:1343-52. 